\title{
Intermediate uveitis, posterior uveitis, and panuveitis in the Mid-Atlantic USA
}

\author{
This article was published in the following Dove Press journal: \\ Clinical Ophthalmology \\ 25 August 2015 \\ Number of times this article has been viewed
}

\section{Stephanie B Engelhard \\ Vandan Patel \\ Ashvini K Reddy}

Department of Ophthalmology, University of Virginia, Charlottesville, VA, USA
Correspondence: Ashvini K Reddy Department of Ophthalmology, University of Virginia, I 300 Jefferson Park Avenue, OMS 2860B, Charlottesville, VA 22908, USA

Tel +l 4349240070

Fax + I 4349245180

Email akr5u@virginia.edu
Background: The purpose of this study was to identify the causes, clinical features, and outcomes of intermediate uveitis, posterior uveitis, and panuveitis in patients managed in a mid-Atlantic tertiary care center.

Methods: This was a retrospective observational study of intermediate uveitis, posterior uveitis, and panuveitis patients seen at the University of Virginia from 1984 to 2014.

Results: One hundred and fifty-nine intermediate uveitis, posterior uveitis, and panuveitis patients (237 eyes) were identified. The patient population was $54.72 \%$ female; $67.30 \%$ of patients were Caucasian, and $22.01 \%$ were African-American. Mean age at diagnosis was 45.5 years. Mean duration of follow-up was 3.95 years. Mean number of visits to the clinic was 10.35. Of 491 uveitis patients, $26(5.30 \%)$ had intermediate uveitis, $62(12.60 \%)$ had posterior uveitis, and $71(14.50 \%)$ had panuveitis. The leading diagnoses in the intermediate uveitis group were pars planitis (73.08\%) and sarcoidosis (11.54\%); toxoplasma uveitis (17.74\%), multifocal choroiditis (14.52\%), undifferentiated posterior uveitis (14.52\%), and birdshot chorioretinitis $(11.29 \%)$ in the posterior uveitis group; and undifferentiated panuveitis $(29.58 \%)$, post-surgical panuveitis $(18.31 \%)$, sarcoidosis $(12.68 \%)$, acute retinal necrosis $(12.68 \%)$, and toxoplasma uveitis $(4.23 \%)$ in the panuveitis group. The most common treatment modalities included local steroids (57.23\%) and systemic steroids (42.14\%). Ocular hypertension was found in 38 patients $(23.90 \%)$. Glaucoma surgery was performed in $18.24 \%$ of patients and cataract surgery in $21.38 \%$. Mean best-corrected visual acuity was $0.66 \operatorname{logMAR}$ at baseline across all anatomical locations and $0.57 \log$ MAR at final follow-up. Best-corrected visual acuity improved or remained stable during follow-up in all groups.

Conclusion: The most common diagnoses in our series by anatomical location were pars planitis (intermediate uveitis), toxoplasmosis (posterior uveitis), and undifferentiated uveitis (panuveitis). Panuveitis had significantly worse visual outcomes and higher rates of complications than did intermediate or posterior uveitis, a finding that confirms earlier reports. In this series, unilateral disease, regardless of anatomical location, was associated with poorer visual outcome, in contrast with the findings of other reports.

Keywords: visual acuity, intraocular pressure, toxoplasmosis, acute retinal necrosis, toxoplasmosis, birdshot chorioretinitis

\section{Introduction}

Uveitis represents a heterogeneous group of intraocular inflammatory diseases with a diverse set of infectious and noninfectious etiologies. Uveitis epidemiology varies widely with geographic location; however, it remains a significant cause of vision loss throughout the world. Globally, the uveitides account for up to $25 \%$ of blindness. ${ }^{1}$ In the USA, uveitis causes an estimated 30,000 new cases of legal blindness annually and is responsible for $10 \%-15 \%$ of blindness in the Western world. ${ }^{1-6}$ Complicated uveitis management often requires many clinic visits. This, coupled with the vision 
loss associated with the uveitides represents a great burden to patients and society both financially and in terms of lost productivity and decreased quality of life.

Despite recognition of the risk of blindness with ocular inflammation, reports detailing the incidence, prevalence, and regional patterns of uveitis remain limited in certain areas. There has been increased interest in population-based reports and epidemiological data on uveitis in recent years, which have led to a more comprehensive understanding of ocular inflammation and its etiologies. ${ }^{7-9}$ Because the development of uveitis and the visual outcomes associated with the uveitides are influenced by a combination of genetics, geography, ethnicity, diagnostic factors, and referral patterns, it is essential to report the regional epidemiology of uveitis in order to characterize the regional characteristics of these disorders to allow for prompt diagnosis and initiation of vision-saving treatment. ${ }^{10}$

Previous studies from around the world have focused on describing the incidence and prevalence of all uveitis etiologies at various referral centers; however, none of them focus only on nonanterior uveitis cases. Although less common in our population than anterior uveitis, intermediate uveitis, posterior uveitis, and panuveitis present significant challenges. There is also some evidence that nonanterior uveitis may result in poorer visual outcomes. ${ }^{11}$ This retrospective observational study was performed in order to report the etiologies, manifestations, and patterns of all intermediate uveitis, posterior uveitis, and panuveitis cases at the University of Virginia, a mid-Atlantic US tertiary referral center over a 30-year period, and to analyze the causes, clinical features, and outcomes in this population.

\section{Materials and methods}

This was a retrospective observational study of all patients with intermediate uveitis, posterior uveitis, and panuveitis seen in the Department of Ophthalmology at the University of Virginia. The study was approved by the University of Virginia Institutional Review Board and was conducted in accordance with the principles of the Declaration of Helsinki. This was a retrospective chart review study with a Health Insurance Portability and Accountability Act waiver and did not need patient consent.

A database of all patients with a diagnosis of uveitis is maintained in the Department of Ophthalmology at the University of Virginia and includes 491 patients. The database was reviewed to identify patients diagnosed with intermediate uveitis, posterior uveitis, and panuveitis over a 30-year period from 1984 through 2014. One hundred and fifty-nine intermediate uveitis, posterior uveitis, and panuveitis patients were identified from the database. No minimum follow-up period was required for inclusion, and all data in the database were collected from patient charts completed at the time of patient visits. Time points for data collection in the database included each patient's initial visit to the clinic (baseline) and final follow-up visit. Disease classification was recorded in accordance with the Standardization of Uveitis Nomenclature Working Group criteria. ${ }^{12}$

The database was reviewed for patient demographic information including date of birth, sex, race/ethnicity, age at presentation, duration of follow-up, and number of clinic visits. Clinical information including final diagnosis with etiology, location, laterality, and chronicity of uveitis, best-corrected visual acuity (BCVA), intraocular pressure (IOP), laboratory findings, relevant systemic and associated diagnoses, treatment modalities, and complications was also reviewed. BCVA results were converted to logarithm of the minimum angle of resolution (logMAR) units for analysis and are given as $\log$ MAR (mean \pm standard deviation). Visual acuity of counting fingers was recorded as $2.0 \log$ MAR; hand movements, $2.3 \log$ MAR; light perception, $2.6 \log$ MAR; and no light perception, $2.9 \operatorname{logMAR} .^{13,14}$ Good visual outcome was defined as visual acuity (VA) of $\geq 20 / 40$, moderate visual impairment was defined as a VA between 20/50 and 20/200, and severe visual impairment was defined as VA worse than 20/200. ${ }^{12}$ Uveitis etiologies were confirmed by imaging with optical coherence tomography, fluorescein angiography, and automated perimetry, and by further ancillary testing including serology, radiology, microbiology, and biopsy when appropriate. Intraocular infection was confirmed with fluid sampling or biopsy for microscopy and cytology and culture or polymerase chain reaction, when appropriate. Management including the use of local and systemic steroids, antihypertensive drops, intravitreal injections, subtenon injections, antimetabolites, anti-tumor necrosis factor agents, cataract surgery, pars plana vitrectomy, and glaucoma management (medical and surgical intervention) were recorded. Descriptive statistical analysis was performed where appropriate.

\section{Results}

A review of all 491 patients diagnosed with uveitis at the University of Virginia between 1984 and 2004 was conducted. One hundred and fifty-nine patients (237 eyes) diagnosed with intermediate uveitis, posterior uveitis, or panuveitis were identified from the 491 patients $(32.4 \%)$ and analyzed. Of the 159 patients, $87(54.72 \%)$ were female. One hundred and seven patients (67.30\%) were Caucasian, 35 (22.01\%) were African-American, three (1.89\%) were Hispanic, and 
$14(8.81 \%)$ were of another race. The mean age at diagnosis of uveitis was $45.5 \pm 21.66$ years, and the mean age at presentation to the ophthalmology clinic at the University of Virginia was $44.6 \pm 21.20$ years. Mean duration of follow-up was $3.95 \pm 6.31$ years. Total follow-up ranged from 1 day to 30 years. Mean number of visits to the ophthalmology clinic was 10.35 \pm 12.04 (range 1-71). The intermediate uveitis group had the youngest age at diagnosis of 33.2 \pm 19.26 years, the youngest age at presentation at $32.6 \pm 18.33$ years, and the lowest number of clinic visits at $8.62 \pm 7.26$. The panuveitis group had the oldest age on diagnosis at $50.5 \pm 21.43$ years and the oldest age on presentation at $50.2 \pm 21.70$ years. Patient demographic information and characteristics by anatomical location and overall are summarized in Table 1.

Ninety-eight eyes from 71 patients were diagnosed with panuveitis, which was the most common anatomical location. Intermediate uveitis was present in 45 eyes of 26 patients, and posterior uveitis was present in 94 eyes of 62 patients. A summary of anatomical locations from the current series as well as a comparison with other major US epidemiological studies is found in Table 2 .

The most common diagnosis in the intermediate uveitis group ( $\mathrm{n}=26)$ was pars planitis $(\mathrm{n}=19,73.08 \%)$. The most common posterior uveitis diagnoses were toxoplasma uveitis $(\mathrm{n}=11$, $17.74 \%$ ), multifocal choroiditis ( $n=9,14.52 \%)$, undifferentiated posterior uveitis ( $n=9,14.52 \%)$, and birdshot chorioretinitis $(n=7$,
$11.29 \%$ ). The most common diagnoses in the panuveitis group were undifferentiated panuveitis $(n=23,32.39 \%)$, post-surgical panuveitis ( $\mathrm{n}=13,18.31 \%$ ), panuveitis secondary to sarcoidosis $(n=9,12.68 \%)$, and acute retinal necrosis $(n=9,12.68 \%)$. A summary of common diagnoses can be found in Table 3 .

Ophthalmic management and interventions were documented. During the follow-up period, 91 of 159 patients $(57.23 \%)$ were prescribed local steroids, which was the most common treatment. Similar percentages of the intermediate and panuveitis groups were prescribed local steroids, at $69.23 \%$ and $70.42 \%$ respectively; however, only $37.10 \%$ of the posterior uveitis group was prescribed local steroids. Patients treated with anti-tumor necrosis factor agents were diagnosed with ankylosing spondylitis-related uveitis, sarcoidosis, toxoplasmosis, and undifferentiated uveitis. The panuveitis group received significantly higher rates of glaucoma and cataract treatment than did the intermediate uveitis and posterior uveitis groups. While 38.03\% of the panuveitis group was prescribed topical glaucoma treatment, only $15.38 \%$ of the intermediate uveitis group and $20.97 \%$ of the posterior uveitis groups were prescribed this treatment. Similarly, glaucoma surgery was performed in significantly more panuveitis uveitis cases than in either of the other groups, with $32.39 \%$ in the panuveitis group versus only $3.85 \%$ in the intermediate group and $8.06 \%$ in the posterior uveitis group. While low percentages of the intermediate

Table I Patient demographics, uveitis characteristics, clinical measurements, and outcomes by site of ocular inflammation

\begin{tabular}{|c|c|c|c|c|}
\hline & $\begin{array}{l}\text { Intermediate uveitis } \\
(n=26)(16.35 \%)\end{array}$ & $\frac{\text { Posterior uveitis }}{(n=62)(38.99 \%)}$ & $\begin{array}{l}\text { Panuveitis } \\
(n=7 I)(44.65 \%)\end{array}$ & $\begin{array}{l}\text { All sites } \\
(n=159)(100 \%)\end{array}$ \\
\hline \multicolumn{5}{|l|}{$\operatorname{Sex}(\%)$} \\
\hline Male & $10(38.46)$ & $31(50.00)$ & $31(43.66)$ & $72(45.28)$ \\
\hline Female & $16(6 \mid .54)$ & $31(50.00)$ & $40(56.34)$ & $87(54.72)$ \\
\hline \multicolumn{5}{|l|}{ Race/ethnicity (\%) } \\
\hline Caucasian & $19(73.08)$ & $43(69.35)$ & $45(63.38)$ & $107(67.30)$ \\
\hline African-American & $4(15.38)$ & II (I7.74) & $20(28.17)$ & 35 (22.0I) \\
\hline Hispanic & $0(0)$ & $3(4.84)$ & $0(0)$ & $3(1.89)$ \\
\hline Other & $3(1 \mathrm{I} .54)$ & $5(8.06)$ & $6(8.45)$ & I4 (8.8I) \\
\hline Mean age (years) at diagnosis of uveitis $( \pm S D)$ & $33.2(19.26)$ & $43.6(19.52)$ & $50.5(21.43)$ & $45.5(21.66)$ \\
\hline Mean age (years) at presentation $( \pm S D)$ & $32.6(18.33)$ & $41.8(17.88)$ & $50.2(21.70)$ & $44.6(21.20)$ \\
\hline Mean duration (years) of follow-up ( \pm SD) & $3.9(5.49)$ & $4.24(7.17)$ & $3.72(5.90)$ & $3.95(6.31)$ \\
\hline Mean number of ophthalmology clinic visits $( \pm S D)$ & $8.62(7.26)$ & II.05 (13.52) & $10.37(12.15)$ & $10.35(12.04)$ \\
\hline \multicolumn{5}{|l|}{ Uveitis laterality $(\%)$} \\
\hline Bilateral & $19(73.08)$ & $32(51.62)$ & $27(38.03)$ & $78(49.06)$ \\
\hline Unilateral & $7(26.92)$ & 30 (48.39) & $44(6 I .97)$ & $81(50.94)$ \\
\hline \multicolumn{5}{|l|}{ Clinical measures and visual outcomes } \\
\hline Initial logMAR BCVA ( \pm SD) & $0.5 \mathrm{I}(0.8 \mathrm{I})$ & $0.43(0.50)$ & $0.95(1.01)$ & $0.66(0.84)$ \\
\hline Final logMAR BCVA ( \pm SD) & $0.23(0.37)$ & $0.43(0.69)$ & $0.87(1.06)$ & $0.57(0.85)$ \\
\hline Initial IOP $( \pm \mathrm{SD})$ & $14.60(4.95)$ & $15.30(6.19)$ & | 4.77 (5.77) & $14.95(5.78)$ \\
\hline Final IOP $( \pm$ SD) & $13.88(3.73)$ & $15.22(4.3 \mid)$ & 15.05 (7.23) & $14.90(5.63)$ \\
\hline
\end{tabular}

Abbreviations: BCVA, best-corrected visual acuity; IOP, intraocular pressure; logMAR, logarithm of the minimum angle of resolution; SD, standard deviation. 
Table 2 Intermediate uveitis, posterior uveitis, and panuveitis distribution in key US studies*

\begin{tabular}{|c|c|c|c|c|c|c|}
\hline & $\begin{array}{l}\text { Present study } \\
(n=491)\end{array}$ & $\begin{array}{l}\text { Gritz and Wong }{ }^{15} \\
(n=3 \mid 0) * *\end{array}$ & $\begin{array}{l}\text { Oruc et } a l^{8} \\
(n=853)\end{array}$ & $\begin{array}{l}\text { Rodriguez et } \mathrm{al}^{16} \\
(\mathrm{n}=1,237)\end{array}$ & $\begin{array}{l}\text { Merrill et } \mathrm{al}^{7} \\
(\mathrm{n}=385)\end{array}$ & $\begin{array}{l}\text { Henderly et } \mathrm{al}^{17} \\
(\mathrm{n}=600)\end{array}$ \\
\hline Anterior uveitis & $67.60 \%$ & $86.50 \%$ & $22.27 \%$ & $51.50 \%$ & $25.00 \%$ & $27.80 \%$ \\
\hline Intermediate uveitis & $5.30 \%$ & $3.60 \%$ & $11.02 \%$ & $13.10 \%$ & $12.00 \%$ & $15.40 \%$ \\
\hline Posterior uveitis & $12.60 \%$ & $2.60 \%$ & $48.53 \%$ & $19.40 \%$ & $24.00 \%$ & $38.40 \%$ \\
\hline Panuveitis & $14.50 \%$ & $6.10 \%$ & $18.17 \%$ & $16.00 \%$ & $38.00 \%$ & $18.40 \%$ \\
\hline
\end{tabular}

Notes: *Anterior uveitis percentages included here for reference. ${ }^{* * N}$ Numbers reflect data with indeterminate location cases removed.

uveitis group (11.54\%) and posterior uveitis group (14.52\%) received cataract surgery, a much higher percentage of the panuveitis group did so (30.99\%). Ophthalmic management and interventions by anatomical location are summarized in Table 4.

BCVA was recorded at each patient's initial and final visit and converted to $\log$ MAR. Initial $\log M A R$ across all anatomical locations was $0.66 \pm 0.84 \log$ MAR and the final

Table 3 Common intermediate uveitis, posterior uveitis, and panuveitis diagnoses

\begin{tabular}{ll}
\hline Diagnosis & $\mathbf{n}(\%)$ \\
\hline Intermediate uveitis & \\
Pars planitis & $19(73.08)$ \\
Sarcoidosis & $3(\mathrm{II} .54)$ \\
Ankylosing spondylitis & $\mathrm{I}(3.85)$ \\
Post-surgical & $\mathrm{I}(3.85)$ \\
Posterior uveitis & \\
Toxoplasmosis & $\mathrm{II}(\mathrm{I} 7.74)$ \\
Multifocal choroiditis & $9(\mathrm{I} 4.52)$ \\
Undifferentiated & $9(\mathrm{I} 4.52)$ \\
Birdshot chorioretinitis & $7(\mathrm{II} .29)$ \\
Acute retinal necrosis & $4(6.45)$ \\
Serpiginous choroiditis & $3(4.84)$ \\
APMPPE & $3(4.84)$ \\
MEWDS & $3(4.84)$ \\
Sarcoidosis & $2(3.23)$ \\
CMV posterior uveitis & $2(3.23)$ \\
Ulcerative colitis & $\mathrm{I}(\mathrm{I} .6 \mathrm{I})$ \\
Polyarteritis nodosa & $\mathrm{I}(\mathrm{I} .6 \mathrm{I})$ \\
Syphilis & $\mathrm{I}(\mathrm{I} .6 \mathrm{I})$ \\
Eales disease & $\mathrm{I}(\mathrm{I} .6 \mathrm{I})$ \\
Panuveitis & \\
Undifferentiated & $23(32.39)$ \\
Post-surgical & $\mathrm{I}(\mathrm{I} 8.3 \mathrm{I})$ \\
Sarcoidosis & $9(\mathrm{I} 2.68)$ \\
Acute retinal necrosis & $9(\mathrm{I} 2.68)$ \\
Toxoplasmosis & $3(4.23)$ \\
Fungal & $3(4.23)$ \\
Herpetic panuveitis & $2(2.82)$ \\
Tuberculosis & $2(2.82)$ \\
Crohn's disease & $\mathrm{I}(\mathrm{I} .4 \mathrm{I})$ \\
Trauma & $\mathrm{I}(\mathrm{I} .4 \mathrm{I})$ \\
\hline & $\mathrm{I}(\mathrm{I} .4 \mathrm{I})$ \\
\hline
\end{tabular}

Abbreviations: APMPPE, acute posterior multifocal placoid pigment epitheliopathy; CMV, cytomegalovirus; MEWDS, multiple evanescent white dot syndrome. score was $0.57 \pm 0.85 \log M A R$. The intermediate and panuveitis groups demonstrated an improvement in VA at the final visit. The average final VA in the intermediate uveitis group was $0.23 \pm 0.37 \log M A R$, a significant improvement from the average presenting VA in this group of $0.51 \pm 0.81 \log$ MAR. The average VA in the panuveitis group also improved at final follow-up, although the improvement was less dramatic, being $0.95 \pm 1.01 \log$ MAR at presentation compared with $0.87 \pm 1.06 \log \mathrm{MAR}$ at the final follow-up. In contrast, the average VA for the posterior uveitis group remained constant, with an average presenting VA of $0.43 \pm 0.50 \log$ MAR compared with an average final VA of $0.43 \pm 0.69 \log$ MAR. BCVA outcomes are summarized in Table 1. VA data were also categorized into categories of visual function at the final follow-up visit. Overall, 55.3\% of eyes had a good visual outcome at final follow-up, while $24.9 \%$ had moderate visual impairment and $19.8 \%$ had severe visual impairment at final follow-up. Visual outcomes and impairment by anatomical location are summarized in Table 5.

Initial and final IOP measurements were also recorded. Overall, initial and final IOP measurements were stable at $14.95 \pm 5.78 \mathrm{mmHg}$ initially and $14.90 \pm 5.63 \mathrm{mmHg}$ at the final visit. Both the intermediate uveitis and posterior uveitis groups demonstrated a modest decrease in IOP from baseline to the final visit. In the intermediate uveitis group, initial IOP was $14.60 \pm 4.95 \mathrm{mmHg}$ and final IOP was slightly decreased at $13.88 \pm 3.73 \mathrm{mmHg}$. In the posterior uveitis group, initial IOP was $15.30 \pm 6.19 \mathrm{mmHg}$ and final IOP was $15.22 \pm 4.31$ $\mathrm{mmHg}$. In the panuveitis group, there was a slight increase in IOP from $14.77 \pm 5.77 \mathrm{mmHg}$ to $15.05 \pm 7.23 \mathrm{mmHg}$ at the final visit. Overall, there were 19 eyes with IOP $>21$ $\mathrm{mmHg}$ at the final visit, and six eyes with IOP $\leq 7 \mathrm{mmHg}$ at the final follow-up visit. IOP outcomes are summarized in Table 1.

\section{Discussion}

This retrospective study seeks to report and compare the demographics, etiologies, treatments, and outcomes of a population of 159 intermediate uveitis, posterior uveitis, and panuveitis patients at a tertiary referral center in Virginia 
Table 4 Treatments and interventions by anatomical location

\begin{tabular}{|c|c|c|c|c|}
\hline $\begin{array}{l}\text { Treatments/ } \\
\text { interventions n (\%) }\end{array}$ & $\begin{array}{l}\text { Intermediate uveitis } \\
(\mathrm{n}=26)\end{array}$ & $\begin{array}{l}\text { Posterior uveitis } \\
(n=62)\end{array}$ & $\begin{array}{l}\text { Panuveitis } \\
(n=7 I)\end{array}$ & $\begin{array}{l}\text { Total } \\
(n=159)\end{array}$ \\
\hline Local steroids & $18(69.23)$ & $23(37.10)$ & $50(70.42)$ & $91(57.23)$ \\
\hline Systemic steroids & $12(46.15)$ & $22(35.48)$ & $33(46.48)$ & $67(42.14)$ \\
\hline Antimetabolites & $7(26.92)$ & $10(16.13)$ & $10(14.08)$ & $27(16.98)$ \\
\hline Anti-TNF agents & $3(11.54)$ & $2(3.23)$ & $2(2.82)$ & $7(4.40)$ \\
\hline Subtenon injection & $2(7.69)$ & $3(4.84)$ & $7(9.86)$ & $12(7.55)$ \\
\hline Intravitreal injection & $4(15.38)$ & $12(19.35)$ & $17(23.94)$ & $33(20.75)$ \\
\hline Glaucoma topical treatment & $4(15.38)$ & $13(20.97)$ & $21(38.03)$ & $38(23.90)$ \\
\hline Glaucoma surgery & I (3.85) & $5(8.06)$ & $23(32.39)$ & $29(18.24)$ \\
\hline Cataract surgery & $3(11.54)$ & $9(14.52)$ & $22(30.99)$ & $34(21.38)$ \\
\hline Pars plana vitrectomy & $3(11.54)$ & $\mathrm{I}(1.6 \mathrm{I})$ & $6(8.45)$ & $10(6.29)$ \\
\hline
\end{tabular}

Abbreviation: TNF, tumor necrosis factor.

with those of other populations published in the literature. A comparison of anatomical location of uveitis in the current series with other key US studies is found in Table 2. Over a 30-year period, 491 patients with uveitis were seen at the ophthalmology clinic at the University of Virginia. Of those 491 patients, 159 (32.38\%) received a diagnosis of intermediate uveitis, posterior uveitis, or panuveitis.

To our knowledge, this is the first epidemiological report of intermediate uveitis, posterior uveitis, and panuveitis in the Mid-Atlantic USA. In 1997, Duke University (one of the closest eye centers to ours in Virginia) published an epidemiological report on cases of uveitis seen at its tertiary care center in North Carolina. ${ }^{7}$ In their series of 385 patients, intermediate uveitis was found in $12 \%$ of patients, posterior uveitis in $24 \%$, and panuveitis in $38 \%$.

The authors suggested that the high rate of panuveitis was in part due to a higher frequency of sarcoidosis in their large African-American population base. Gritz and Wong showed that in their Northern California population, intermediate uveitis was found in $3.6 \%$ of cases, posterior uveitis in $2.6 \%$, and panuveitis in $6.1 \% .{ }^{15}$ Another series of 853 uveitis patients in the American Mid-West reported intermediate uveitis in $11.02 \%$ of patients, posterior uveitis in $48.53 \%$, and panuveitis in $18.17 \% .{ }^{8}$ In our population, $5.30 \%$ of patients had intermediate uveitis, $12.6 \%$ has posterior uveitis, and $14.50 \%$ had panuveitis. The differences in prevalence of the various anatomical locations can be attributed to the wide variety of uveitis etiologies and the variations in genetics and environmental factors within the populations studied. The distribution of uveitis cases does not only vary geographically, but has also shifted over time within the USA. ${ }^{16-20}$ In a San Francisco study conducted in 1954, intermediate uveitis accounted for $7.5 \%$ of cases, posterior uveitis for $49 \%$, and panuveitis for $2 \% .{ }^{18} \mathrm{~A}$ similarly high proportion of posterior uveitis cases was found in an Ohio study in 1969, which reported posterior uveitis in $67.7 \%$ of cases. ${ }^{20}$

Like subtype distribution, uveitis etiologies vary geographically and historically. In our series, toxoplasma uveitis accounted for $17.74 \%$ of posterior uveitis cases and $4.23 \%$ of panuveitis cases. Due to the variable prevalence of Toxoplasma gondii in different parts of the world, our findings are at variance with many other reports. In the USA, studies show that the seroprevalence for $T$. gondii is $9.0 \%$ for US-born persons aged $12-49$ years. ${ }^{21}$ In contrast, ocular toxoplasmosis was the leading cause of posterior uveitis in Tunisia (38.3\%) and in Paris (39\%). ${ }^{22,23}$ Furthermore, Ronday et al found that toxoplasmosis was the cause of uveitis in 40 of 93 patients in their series. ${ }^{24}$ Less exposure to the organism in our study population explains the lower prevalence of posterior uveitis and panuveitis in this study relative to areas where $T$. gondii is more prevalent. Cytomegalovirus (CMV) uveitis was associated with $3.23 \%$ of posterior uveitis cases and $2.82 \%$ of panuveitis cases in our series, which is higher than in a Japanese study that reported CMV uveitis in

Table 5 Visual acuity at final follow-up by anatomical location

\begin{tabular}{llll}
\hline Location & $\geq \mathbf{2 0 / 4 0}$ & $\mathbf{2 0 / 5 0 - 2 0 / 2 0 0}$ & $<\mathbf{2 0 / 2 0 0}$ \\
& $\mathbf{n}(\%)$ & $\mathbf{n ~ ( \% )}$ & $\mathbf{n}(\%)$ \\
\hline Intermediate uveitis ( $\mathrm{n}=45$ eyes) & $35(77.8)$ & $\mathbf{7}(15.6)$ & $3(6.7)$ \\
Posterior uveitis ( $\mathrm{n}=94$ eyes) & $55(58.5)$ & $26(27.7)$ & $13(13.8)$ \\
Panuveitis ( $\mathrm{n}=98$ eyes) & $41(41.8)$ & $26(26.5)$ & $31(31.6)$ \\
Total (n=237 eyes) & $131(55.3)$ & $59(24.9)$ & $47(19.8)$ \\
\hline
\end{tabular}


$0.6 \%$ of posterior uveitis and in no cases of panuveitis. ${ }^{25}$ In the current series, sarcoidosis was identified as the cause of $11.54 \%$ of intermediate uveitis, $3.23 \%$ of posterior uveitis, and $12.68 \%$ of panuveitis. In a Duke study, there were lower numbers of intermediate and posterior sarcoidosis uveitis cases, but a much higher number of sarcoid-associated panuveitis cases $(27 \%)^{7}$

In our study, the most common diagnosis received by intermediate uveitis patients was pars planitis (73.08\%), which is consistent with other reports in the literature, which report pars planitis in most intermediate uveitis patients, from $74 \%$ in St Louis to $98 \%$ at Duke. ${ }^{7,8}$ Sarcoidosis uveitis was found in $11.54 \%$ of our intermediate uveitis patients, which also falls within the relatively wide range reported in the literature. A Duke study reported sarcoidosis uveitis in $2 \%$ of intermediate uveitis patients, and a Boston study reported intermediate uveitis secondary to sarcoidosis in $22 \%$ of patients. ${ }^{7,16} \mathrm{Mul}-$ tifocal choroiditis was a common diagnosis in our posterior population, representing $14.52 \%$ of this group. Birdshot chorioretinitis was found in $11.29 \%$ of our posterior uveitis patients, which is slightly higher than other studies, which report birdshot chorioretinitis in 3\%-7.9\% of patients. ${ }^{7,8,16}$

In our series, patients in the panuveitis group were more likely to have unilateral disease, while patients in the intermediate uveitis group were more likely to have bilateral disease. A previous study in the UK found that patients with bilateral disease were more likely to have poor outcomes than those with unilateral disease; however, we found the opposite to be true. ${ }^{11}$ In our series, patients in all groups with unilateral disease had significantly worse visual outcomes than those with bilateral disease. In the intermediate uveitis group, final BCVA was $0.19 \pm 0.31 \log$ MAR in the bilateral group and $0.47 \pm 0.54 \log$ MAR in the unilateral group. Similarly, in the posterior uveitis group, final BCVA was 0.33 $\pm 0.40 \log \mathrm{MAR}$ in the bilateral group and $0.68 \pm 1.03 \log$ MAR in the unilateral group; in the panuveitis group, final BCVA was $0.61 \pm 0.94$ $\log$ MAR in the bilateral group and much worse at $1.18 \pm 1.12$ $\log$ MAR in the unilateral group.

The average age at diagnosis was lowest in the intermediate uveitis group and highest in the panuveitis group. This is consistent with a report from the US Mid-West which found that the mean age of onset of intermediate uveitis was 33.0 years, while the mean age of onset was later in for posterior uveitis at 39.0 years and for panuveitis at 58.0 years. ${ }^{8}$ Similarly, in our series, the average age at diagnosis in the intermediate uveitis group was 33.2 years, and was older in the posterior uveitis group (43.6 years) and in the panuveitis group (50.5 years).

Rates of complications have been discussed in previous studies. One study reported that $5 \%$ of vision loss across all anatomical locations of uveitis was due to glaucoma. ${ }^{11}$ In our series, the percentage of patients with glaucoma was higher, but this is most likely due to our exclusion of anterior uveitis cases, which in general have lower rates of complications than other anatomical locations. Overall, 23.90\% of our intermediate uveitis, posterior uveitis, and panuveitis patients received topical treatment for glaucoma, and 18.24\% underwent glaucoma surgery. These high numbers are mostly due to our high numbers of posterior uveitis and panuveitis patients, who had a much higher rate of glaucoma than the intermediate uveitis patients. In that group, $15.38 \%$ of patients received topical treatment for glaucoma and only $3.85 \%$ underwent glaucoma surgery. In contrast, $20.97 \%$ of the posterior uveitis group and $38.03 \%$ of the panuveitis group received topical glaucoma treatment, and 8.06\% and $32.39 \%$ in the posterior uveitis and panuveitis groups, respectively, underwent glaucoma surgery.

VA improved overall from $0.66 \pm 0.84 \log$ MAR at presentation to $0.57 \pm 0.85 \log \mathrm{MAR}$ at the final visit. The intermediate uveitis group had the greatest improvement in VA from the initial visit $(0.51 \pm 0.81 \log \mathrm{MAR})$ to the final visit $(0.23 \pm 0.37 \log \mathrm{MAR})$. This group also had the best visual outcome. Initial and final VA remained constant during the follow-up period in the posterior uveitis group. Final VA in this group was $0.43 \pm 0.69 \log$ MAR. The poorest visual outcomes were seen in the panuveitis group, which had a final VA of $0.87 \pm 1.06 \log$ MAR. This is consistent with other papers in the literature, which also report that panuveitis is associated with greater vision loss than intermediate uveitis or posterior uveitis. ${ }^{8,11}$

In terms of degree of visual impairment at the final follow-up, the intermediate uveitis group had the most favorable visual outcomes, with $77.8 \%$ having a good visual outcome of 20/40 or better at the final visit. The panuveitis group had the poorest visual outcomes, with $31.6 \%$ of that group having severe visual impairment at the final visit.

The major limitation of this study is its retrospective nature, which increased susceptibility to referral, treatment, and data collection biases. The ophthalmology clinic at the University of Virginia sees patients from the entire state of Virginia as well as referrals from other areas. Furthermore, our health system is located in Charlottesville, Virginia, which is an International Rescue Committee site for international refugees. These patients may affect the results in this study by altering the genetic, racial, and geographic predispositions to diseases associated with uveitis in our population. Because there was not a standardized follow-up period required for inclusion in the study, it is possible that the visual and IOP outcomes represent only patients with 
more severe disease or those with longer follow-up periods. Owing also to the 30-year span of this study, patients were seen by different ophthalmologists. Because of this, and because of the fact that some of the data were taken from a time prior to efforts to standardize the uveitis nomenclature, there was possibly some discrepancy in the categorization of uveitis subtype over time. Additionally, a lack of a uveitis specialist to make precise diagnoses at various times during the 30-year period may have influenced the diagnoses and management of patients. Due to the above limitations, statistical analysis was descriptive in nature.

In conclusion, this series demonstrates the vast differences in etiology, management, and outcomes among different anatomical locations of uveitis. In particular, this study found that panuveitis has significantly worse visual outcomes and a greater risk of complications than intermediate uveitis or posterior uveitis, a finding that echoes other reports in the literature. ${ }^{8,11}$ We also found that visual outcome was worse across all anatomical locations in patients with unilateral disease than in those with bilateral disease, a finding that contrasts with the findings of another report. ${ }^{11}$

\section{Acknowledgments}

Asima Bajwa and Irfan Khan assisted with data collection.

\section{Disclosure}

The authors report no conflicts of interest in this work.

\section{References}

1. Abdulaal M, Antonios R, Barikian A, Jaroudi M, Hamam RN. Etiology and clinical features of ocular inflammatory diseases in a tertiary center in Lebanon. Ocul Immunol Inflamm. June 9, 2014. [Epub ahead of print].

2. Nussenblatt RB. The natural history of uveitis. Int Ophthalmol. 1990; 14(5-6):303-308.

3. Acharya NR, Tham VM, Esterberg E, et al. Incidence and prevalence of uveitis: results from the Pacific Ocular Inflammation Study. JAMA Ophthalmol. 2013;131(11):1405-1412.

4. Rothova A, Suttorp-Van Schulten MS, Treffers WF, Kijlstra A. Causes and frequency of blindness in patients with intraocular inflammatory disease. Br J Ophthalmol. 1996;80(4):332-336.

5. Suttorp-Schulten MS, Rothova A. The possible impact of uveitis in blindness: a literature survey. Br J Ophthalmol. 1996;80(9):844-848.
6. Suhler EB, Lloyd MJ, Choi D, Rosenbaum JT, Austin DF. Incidence and prevalence of uveitis in Veterans Affairs Medical Centers of the Pacific Northwest. Am J Ophthalmol. 2008;146(6):890-896.

7. Merrill PT, Kim J, Cox TA, Betor CC, McCallum RM, Jaffe GJ. Uveitis in Southeastern United States. Curr Eye Res. 1997;16:865-874.

8. Oruc S, Kaplan AD, Galen M, Kaplan HJ. Uveitis referral pattern in a Midwest University Eye Center. Ocul Immunol Inflamm. 2003;11(4): 287-298.

9. McCannelCA,HollandGN, Helm CJ, CornellPJ, Winston JV, RimmerTG. Causes of uveitis in the general practice of ophthalmology. UCLA Community-Based Uveitis Study Group. Am J Ophthalmol. 1996; 121(1):35-46.

10. Weiner A, BenEzra D. Clinical patterns and associated conditions in chronic uveitis. Am J Ophthalmol. 1991;112(2):151-158.

11. DurraniOM, Tehrani NN, Marr JE, MoradiP, StavrouP, Murray PI. Degree, duration, and causes of visual loss in uveitis. Br JOphthalmol. 2004;88(9): 1159-1162.

12. Standardization of Uveitis Nomenclature (SUN) Working Group. Standardization of uveitis nomenclature for reporting clinical data. Results of the First International Workshop. Am J Ophthalmol. 2005;140(3): 509-516.

13. Lange C, Feltgen N, Junker B, Schulze-Bonsel K, Bach M. Resolving the clinical acuity categories "hand motion" and "counting fingers" using the Freiburg visual acuity test (FrACT). Graefes Arch Clin Exp Ophthalmol. 2009;247(1):137-142.

14. Kwon YH, Kim CS, Zimmerman MB, Alward WL, Hayreh SS. Rate of visual field loss and long-term visual outcome in primary open-angle glaucoma. Am J Ophthalmol. 2001;132(1):47-56.

15. Gritz GC, Wong IG. Incidence and prevalence of uveitis in Northern California. Ophthalmology. 2004;111(3):491-500.

16. Rodriguez A, Calonge M, Pedroza-Seres M, et al. Referral patterns of uveitis in a tertiary eye care center. Arch Ophthalmol. 1996;114(5): 593-599.

17. Henderly OE, Genstler AJ, Smith RE, Rao NA. Changing patterns of uveitis. Am J Ophthalmol. 1987;103(2):131-136.

18. Kimura S, Hogan MJ, Thygeson P. Uveitis in children. Am J Dis Child. 1954;87(1):40-48.

19. Perkins ES. Pattern of uveitis in children. Br J Ophthalmol. 1966;50: 169-185.

20. Makley TA, Long J, Suic T. Uveitis in children. J Pediatr Ophthalmol. 1966;50:169-185.

21. Jones JL, Kruszon-Moran D, Sanders-Lewis K, Wilson M. Toxoplasma gondii infectious in the United States, 1999-2004, decline from the prior decade. Am J Trop Med Hyg. 2007;77(3):405-410.

22. Khairallah M, Yahia SB, Ladjimi A, et al. Pattern of uveitis in a referral centre in Tunisia, North Africa. Eye. 2007;21(1):33-39.

23. Bodaghi B, Cassoux N, Wechsler B, et al. Chronic severe uveitis: etiology and visual outcome in 927 patients from a single center. Medicine (Baltimore). 2001;80(4):263-270.

24. Ronday MJ, Stilma JS, Barbe RF, et al. Aetiology of uveitis in Sierra Leone, West Africa. Br J Ophthalmol. 1996;80(11):956-961.

25. Keino H, Nakashima C, Watanabe T, et al. Frequency and clinical features of intraocular inflammation in Tokyo. Clin Exp Ophthalmol. 2009;37(6): 595-601.
Clinical Ophthalmology

\section{Publish your work in this journal}

Clinical Ophthalmology is an international, peer-reviewed journal covering all subspecialties within ophthalmology. Key topics include: Optometry; Visual science; Pharmacology and drug therapy in eye diseases; Basic Sciences; Primary and Secondary eye care; Patient Safety and Quality of Care Improvements. This journal is indexed on Submit your manuscript here: http://www.dovepress.com/clinical-ophthalmology-journal

\section{Dovepress}

PubMed Central and CAS, and is the official journal of The Society of Clinical Ophthalmology (SCO). The manuscript management system is completely online and includes a very quick and fair peer-review system, which is all easy to use. Visit http://www.dovepress.com/ testimonials.php to read real quotes from published authors. 